\title{
O lazer como fator de permanência e reprodução social no meio rural: estudo do município de Saudade do Iguaçu, PR
}

\author{
Leisure as permanence and social reproduction factor in rural areas: \\ study of the municipality of Saudade do Iguaçu, PR
Le loisir comme facteur de permanence et de reproduction sociale dans les zones rurales: étude de la municipalité de Saudade do Iguaçu, PR
El ocio como factor de permanencia y reproducción social en el medio rural: estudio del municipio de Saudade do Iguaçu, PR

\author{
Celí Maziero ${ }^{1}$ \\ Cristiane Maria Tonetto Godoy ${ }^{1}$ \\ José Ricardo da Rocha Campos ${ }^{1}$ \\ Nilvania Aparecida de Mello ${ }^{1}$
}

Recebido em 20/11/2017; revisado e aprovado em 27/04/2018; aceito em 05/05/2018

DOI: http://dx.doi.org/10.20435/inter.v0i0.1763

\begin{abstract}
Resumo: O lazer e as práticas de atividades recreativas no meio rural são consideradas ações secundárias, pois o rural é percebido como sinônimo de área de produção agropecuária. Nesse contexto, a falta de estruturas que propiciem o lazer e até mesmo a influência social, econômica, política e cultural, favorece um novo esvaziamento do rural. O presente artigo tem como objetivo refletir sobre o lazer na área rural e sua respectiva influência na qualidade de vida e na reprodução social das famílias do campo, tendo como foco de estudo o município de Saudade do Iguaçu, Paraná, Brasil.
\end{abstract}

Palavras-chave: lazer; rural; qualidade de vida; famílias do campo.

Abstract: Leisure and recreational activities in rural areas are considered secondary actions, since the rural is perceived as synonymous with agricultural production area. In this context, the lack of structures that favor leisure and even social, economic, political and cultural influence, favor a new emptying of the rural. The objective of this article is to reflect on leisure in the rural area and its respective influence on the quality of life and social reproduction of the rural families, focusing on the city of Saudade do Iguaçu, Paraná, Brazil.

Keywords: leisure; rural; quality of life; rural families.

Résumé: Les activités de loisirs et de loisirs dans les zones rurales sont considérées comme des actions secondaires, car les zones rurales sont perçues comme synonymes de zone de production agricole. Dans ce contexte, le manque de structures favorisant les loisirs et même influence sociale, économique, politique et culturelle, favorise une nouvelle vidange des ruraux. L 'objectif de cet article est de réfléchir aux loisirs dans les zones rurales et à leur influence respective sur la qualité de la vie et la reproduction sociale des familles rurales, en se concentrant sur la ville de Saudade do Iguaçu, Paraná, Brésil.

Mots-clés: loisir; rural; qualite de vie; familles rurales.

Resumen: El ocio y las prácticas de actividades recreativas en el medio rural son consideradas acciones secundarias, pues el rural es percibido como sinónimo de área de producción agropecuaria. En este contexto, la falta de estructuras que propicien el ocio e incluso la influencia social, económica, política y cultural, favorecen un nuevo vaciamiento del rural. El presente artículo tiene como objetivo reflexionar sobre el ocio en el área rural y su respectiva influencia en la calidad de vida y en la reproducción social de las familias del campo, teniendo como foco de estudio el municipio de Saudade do Iguaçu, Paraná, Brasil.

Palabras clave: ocio; rural; calidad de vida; familias del campo.

\footnotetext{
${ }^{1}$ Universidade Tecnológica Federal do Paraná (UTFPR), Pato Branco, Paraná, Brasil.
} 


\section{INTRODUÇÃO}

A sociedade moderna se transformou, saiu de uma sociedade feudal, rural e manufaturada para uma sociedade industrial e urbana. E, nesse processo de mudanças de paradigmas sociais e produtivos, é que teremos a diferenciação do rural versus o urbano, ou seja, do que é entendido como moderno e atrasado. O rural então é denominado como região atrasada e que precisa se modernizar por meio de propostas produtivas homogeneizantes, mecanização, melhoramento genético e adoção de pacotes tecnológicos, processo esse conhecido como Revolução Verde.

Nesse contexto, a configuração da formação do espaço geográfico se dá por esferas com estruturas e finalidades que se distinguem a ponto de serem vistos como ambientes de oposição territorial. A área urbana é expressamente valorizada em detrimento da rural, sendo privilegiada com projetos de infraestruturas e percebida como local de melhor qualidade de vida, oportunidades e lazer. Cabe esclarecermos que as áreas urbanas neste trabalho devem ser compreendidas como as sedes municipais, municípios polos regionais e as capitais.

Nesse sentido, ao rural coube a função da produção agropecuária e do fornecimento da matéria-prima para a indústria, pois os projetos destinados ao campo têm focado apenas no aumento da produtividade e/ou da renda, atualmente agregando as áreas de preservação ambientais. Podemos afirmar que o rural é visto como um mero lugar de relações de trabalho e produção, sem ser concebido na perspectiva humana e social, não existindo, assim, um olhar para a qualidade de vida dos agricultores.

Godoy et al. (2010) destacam que, com a modernização do campo, houve uma mudança nas condições de vida dos agricultores, já que muitos se endividaram e tiveram que se deslocar do rural para os centros urbanos. Corroborando, Hartwing (2012) aponta que a modernização do campo estava baseada em um modelo concentrador de renda, levando a migração da população rural para as cidades em busca de empregos e melhor qualidade de vida.

A população rural vem reduzindo ao longo das décadas, gerando consequências que podem ser visualizadas atualmente no campo, tais como masculinização, envelhecimento, fechamento de escolas rurais e falta de acesso à saúde, entre outros. Portanto a saída do rural é caracterizada por ser um fenômeno que assola diferentes regiões brasileiras, vigorando em um meio de evasão de problemas, sejam eles econômicos, tecnológicos, científicos, ambientais ou sociais. Dessa forma, a literatura é ampla sobre os diversos estudos acerca do êxodo rural ou de suas consequências, podendo ser aferido que a maioria dos trabalhos tem como preocupação central qual(is) o(s) rumo(s) que o rural e a população do campo terão no futuro.

Quando nos referimos à qualidade de vida para as pessoas que residem no campo, extrapolamos o conceito simplista do aumento de renda como bem-estar, compreendemos que a qualidade somente será assegurada quando elas tiverem os mesmos acessos e condições que o espaço urbano, ou seja, acesso à saúde, educação, comunicação, ao esporte, ao lazer e outros, no seu local de moradia e comunidade. Nesse sentido, é necessário pensarmos a permanência e a reprodução das famílias rurais através de estratégias que promovam o lado social e a criação de infraestruturas que atendam essas regiões.

No município de Saudade do Iguaçu, sudoeste do Paraná, tal como em outros municípios predominantemente agrícolas, as atividades de produção nas propriedades rurais são consideradas prioridades, deixando, em segundo plano, a utilização dos ambientes para o lazer, bem como o contato direto e/ou diálogo entre as famílias e demais membros das comunidades. A falta de lazer e do convívio com a comunidade, o que por si só já seria um estímulo para o isolamento, 
também faz com que as propriedades rurais se tornem um local de trabalho em tempo integral, sem um momento de descanso ou convívio social, o que contribui em tornar o trabalho mais penoso e reduzir a qualidade de vida.

Ainda, ao refletirmos sobre os diversos debates e estudos acerca da permanência de quem vive no rural, particularmente dos jovens, podemos aferir que a questão do lazer e do convívio social são de suma importância enquanto estratégias para o fortalecimento e continuação da população no campo. Afinal, ao proporcionar ambientes de lazer e recreações, esses não necessitariam deixar o campo e migrar para os centros urbanos ou capitais para poderem acessar tais condições de relaxamento e divertimento. Outros fatores também auxiliariam na permanência das famílias no campo e na sua reprodução social, como por exemplo, políticas públicas, escolas e hospitais.

Portanto este artigo se propõe a compreender e analisar quais são as atividades de lazer, entretenimento e recreação presentes na área rural do município de Saudades do Iguaçu/PR, bem como sua influência na qualidade de vida das famílias inseridas nesse ambiente. Ainda, através do estudo, pretendemos contribuir com a temática, possibilitando as transformações nesse meio, induzindo a valorização do planejamento rural, a permanência e o fortalecimento das famílias campesinas.

\section{CONHECENDO A REGIÃO E A METODOLOGIA}

A pesquisa foi realizada no município de Saudade do Iguaçu, na região Sudoeste do estado do Paraná, Brasil, e possui uma área territorial de 152,085 km², com uma população equivalente a 5.028 habitantes (censo de 2010), população estimada de 5.410 habitantes em 2016 e densidade demográfica de 33,06 hab/ $\mathrm{km}^{2}$. Em relação aos moradores saudadenses, o município encontra-se proporcionalmente dividido em rural e urbano, com 2.500 habitantes na área rural, estratificados em 114 famílias (IBGE, 2017).

Na produção agropecuária, predominam pequenos e médios estabelecimentos com mão de obra familiar, caracterizando assim a diversidade produtiva, e um sistema de produção de leite e grãos principalmente (IBGE, 2017). O município atualmente conta como ponto turístico, a Usina Hidrelétrica Salto Santiago, formando um grande lago chamado de Alagado, tornando-se atrativo para a população urbana local e para os municípios vizinhos, que veem na região oportunidades de lazer com eventos náuticos e pesca, além da formação de condomínios residenciais de veraneio para o descanso (SAUDADE DO IGUAÇU, 2017).

A metodologia escolhida para atingirmos o objetivo foi a abordagem qualitativa com enfoque descritivo. A pesquisa qualitativa classifica-se como uma análise cujo embasamento é a compreensão, descrição e identificação dos valores coletados, baseado na interpretação dos fatos, ao invés da sua mensuração. O caráter descritivo, por sua vez, é definido por MatiasPereira (2012) como uma investigação que visa descrever as características inerentes ao grupo ou fenômeno, ou determinar as relações entre variáveis, havendo a padronização de técnicas para a coleta de dados.

Para atingir as diretrizes desta pesquisa, utilizamos como técnica o roteiro de entrevista semiestruturada. Michel (2009) destaca que a entrevista é um instrumento de investigação social que permite o contato face a face, no qual uma pessoa obtém informações de determinado assunto a partir de uma conversação de natureza profissional, proporcionando ao entrevistado os conhecimentos necessários. 
O total de entrevistados foram 26 agricultores da área rural do município em questão, população constituída de ambos os gêneros e selecionada aleatoriamente. Cabe ressaltar que o número de entrevistas não foi pautado em nenhum delineamento estatístico, e os entrevistados foram informados previamente dos objetivos e procedimentos previstos, com o intuito de identificar a percepção desse grupo acerca da influência do lazer na permanência das famílias na área rural, sendo estimulados a expor livremente as suas percepções. O roteiro de entrevista foi composto por 15 questões das mais diferentes áreas de abrangência, no entanto focamos aspectos relacionados às práticas de lazer ofertadas na comunidade, importância do lazer no cotidiano dessas famílias, bem como sugestões de alternativas de entretenimento que poderiam ser implantadas.

A partir das entrevistas, seguimos para a interpretação e compreensão dos dados levantados, empregando análises descritivas baseadas nas informações proferidas pelos entrevistados e, para a tabulação desses dados, utilizamos técnicas de representação como os gráficos. Nesse sentido, esperamos contribuir com a temática do lazer e no debate para a permanência e reprodução social dos agricultores.

\section{CONTEXTUALIZANDO SOBRE O LAZER E O RURAL}

Ao procurarmos sobre o conceito de lazer na literatura, nos deparamos com diversas noções que, muitas vezes, dependem do momento histórico e da constituição da sociedade. Na década de sessenta e pós Segunda Guerra Mundial, a qualidade de vida era compreendida pelo fator econômico do indivíduo ou família, quanto maior a renda, maior seria a qualidade de vida e bem-estar, pois acumularia bens.

Na modernidade, segundo Martignoni (2013), existe o ordenamento da sociedade com o tempo de não trabalho, isso se dá devido às intensas jornadas diárias que marcavam a vida dos trabalhadores e, nesse vínculo de trabalho e tempo livre, é que se estabelece o lazer. O lazer seria o momento destinado aos estudos, à religião e especialmente ao descanso para revigorar as forças produtivas. A partir da intensificação da urbanização e industrialização, foram concretizadas as formas de lazer vivenciadas hoje em dia, geralmente atreladas aos espaços urbanos. Também são criadas, nos centros urbanos, as opções de lazer, como os parques e as praças, que se inspiram na proximidade com a natureza.

A expressão qualidade de vida é habitualmente vinculada, nos estudos sobre lazer, aos indicadores econômicos, educacionais, transporte e saúde, principalmente no meio urbano, ressaltada como uma abordagem universal a todos os sujeitos. Outros autores, por sua vez, propõem que seja estudada dentro de uma cultura específica, considerando as diferentes localidades e grupos (ZIOLI, 2015). Assim, se evidencia que o termo qualidade de vida é relativo, por esse motivo, se torna temerário defini-lo como uma única conceituação, pois varia de acordo com o pensamento e necessidade de cada indivíduo ou cultura a que se refere.

Para Paschoal (2000), a definição de qualidade de vida aliada ao lado econômico sofreu diversas críticas, pois, não necessariamente, a compra de bens constituiria qualidade de vida e momentos de lazer. Para o autor, esse conceito deve ser mais amplo, ele deve considerar o desenvolvimento social, educação, saúde e o próprio lazer. Essa ideia vem contribuir com o pensamento de Nahas (2001), ao relatar que a qualidade de vida atualmente tem valorizado outros aspectos tais como a satisfação, realização pessoal, bem-estar, eventos culturais, relacionamentos e acesso ao lazer. 
Como podemos perceber, a qualidade de vida está atrelada à noção de lazer. Para Oliveira (2004), o lazer pode ser compreendido como aquilo que se constitui em um valor positivo, qualquer atividade ou atitude que proporcione a sensação de bem-estar. Ainda, pode ser uma ação ou atitude com diversos conteúdos e propósitos, sejam eles nos âmbitos intelectuais, lúdicos, criativos, esportivos, socioculturais, políticos ou econômicos, e independem de classe social, raça, crença e gênero.

Dessa forma, o lazer se afirma como um valor social, sinônimo de qualidade de vida e bem-estar de um indivíduo, ainda sendo diretamente associado à felicidade e melhores condições de saúde, já que, nesses períodos, é que liberamos o stress do trabalho e as preocupações do dia a dia, bem como é a partir do lazer e da participação social/cultural que exercemos a cidadania, base para a construção e renovação da sociedade.

Entretanto o lazer como promotor de bem-estar não é somente direito aos centros urbanos, e sim condição sine qua non também para o rural. O rural se transformou, ele pode ser entendido como ambiente pluriativo e multifuncional, não somente como espaço de produção agrícola. Para Godoy e Wizniewsky (2013), com tais mudanças, o rural se torna um local de diversificações de produções, em que emergem novas atividades aliadas à agropecuária, visando a mercados e estratégias de reprodução social e econômica dos moradores, ou seja, deixa de ser considerado exclusivamente sinônimo de área agrícola.

Ao revisarmos a literatura sobre o lazer para a população rural, percebemos alguns fatos importantes: 1 . Os estudos existentes sobre lazer estão focados em sua maioria nos centros urbanos para os operários, idosos e pessoas com deficiências; 2 . Os estudos pesquisam sobre as atividades de lazer no rural com o intuito de um segmento econômico, ecoturismo ou turismo rural como uma atividade lucrativa, ou seja, o turismo rural como uma atividade de trabalho para o agricultor, e não um momento de relaxamento ou gozo; e 3. Algumas pesquisas estão focadas para os idosos no rural, geralmente vinculados aos profissionais da educação física e da saúde na terceira idade.

No que ser refere aos estudos dos idosos rurais e as opções do lazer, Bicalho et al. (2010) assinalam que existem poucas análises sobre esse tema, pois a maioria está relacionada aos centros urbanos. Morais, Rodrigues e Gerhardt (2008), em seu trabalho sobre atividades no lazer para idosos rurais, concluíram que o ambiente rural pode representar maior prevalência de pessoas inativas fisicamente no lazer. Tal decorrência deve-se ao fato de que os idosos vivem em áreas isoladas, com limitações nos transportes, distantes dos recursos sociais (lazer) e de saúde. Corroborando, Pegorari et al. (2015) apontam que, além desses fatores, a população rural expõe mais dedicação ao trabalho e que, nessas comunidades, existe deficiência de espaços e equipamentos para o lazer, o que pode causar um aumento no número de doenças e depressão.

Assim, teremos que o lazer é diretamente responsável pela saúde mental e física dos indivíduos, isto é, pela qualidade de vida, tornando-se elemento básico na constituição da sociedade e das suas políticas públicas. Quando tratamos sobre a realidade rural, teremos que, em muitos casos, o espaço dedicado ao trabalho e à vida são os mesmos, não existe uma separação espacial ou temporal para a labuta/produção e para o lazer, diferentemente do que ocorre com os trabalhadores urbanos. Os momentos de descanso ou recreativos no campo são facilmente confundidos com a jornada de trabalho na propriedade, podendo ser percebido tanto ao acompanhar a família na sua propriedade (prático), quanto nas diversas pesquisas sobre o tecido social rural. 
O meio rural representa o dinamismo e a diversidade da produção e reprodução do modo de vida, contudo verifica-se a importância de indivíduos que se apropriem desses espaços como fonte de relação social e convívio familiar, sem esquecer a identidade cultural que permanece enraizada e ativa no seu cotidiano. Nesse contexto, voltamos à afirmação de que ao rural cabe o trabalho e a labuta e que os momentos de lazer são deixados para outros planos, focando apenas o lado econômico.

Nossa pretensão ao trazer essa breve revisão de literatura sobre lazer no rural é para contribuir com a nossa proposta de reflexão no presente artigo, uma vez que a questão do lazer "no" e "para" o rural tem sido pouco discutida, deixando esse fator ausente nas pesquisas ou tratado exclusivamente para alguns grupos. Contudo acreditamos que a discussão da necessidade do lazer para a população rural possui extrema importância, afinal o lazer é elemento formador da dinâmica e indispensável para a qualidade de vida e permanência das famílias no campo.

\section{LAZER NO RURAL: O QUE TEMOS? UMA DISCUSSÃO SOBRE O TEMA}

Ao iniciarmos as análises e reflexões sobre as entrevistas, ponderamos que o município de Saudade do Iguaçu apresenta aspectos fundamentais a serem abordados ao longo de estudos e pesquisas, devido às potencialidades locais, ao enriquecimento cultural e social da população rural, apesar da sua atual história emancipadora. No Brasil, a desigualdade e a crítica a respeito do lazer se intensificam quando comparadas as vivências das áreas rurais e urbanas, a partir dos programas, projetos e equipamentos provenientes de políticas públicas condizentes com a situação local.

Através dos dados estimados pelo Instituto Brasileiro de Geografia e Estatística (IBGE, 2017), constata-se que o município enfrentou, entre os anos de 2000 e 2010, um dos maiores problemas existente, o êxodo rural. No ano de 2000, possuía um total de 4.608 habitantes, sendo 1.987 da área urbana e 2.621 do meio rural, correspondendo a $43,12 \%$ e $56,88 \%$, respectivamente. Já no ano de 2010, 49,78\% dos 5.028 habitantes saudadenses pertenciam ao perímetro urbano, sendo 1.229 habitantes do sexo masculino e 1.274 do sexo feminino, e 50,22\% ao meio rural, na qual 1.308 homens e 1.217 mulheres. Embora a redução e/ou deslocamento das famílias rurais seja visível, percebemos que seus índices prevalecem sobre a população urbana, demonstrando ainda mais a necessidade de incentivos voltados à permanência desses moradores no meio rural e o aprimoramento das alternativas de lazer.

Dessa forma, na reconstrução do rural, o lazer é classificado por Martignoni (2013) como o elemento primordial, pelo fato de perpassar variadas dimensões de caráter multifuncional na agricultura: reprodução socioeconômica das famílias, preservação dos recursos naturais e do cenário rural, promoção da segurança alimentar e manutenção do tecido social e cultural. Esse fenômeno tem sido apontado como imprescindível na percepção da nova realidade do espaço rural, configurado a partir desse momento não como um lugar de produção agrícola, mas sim para se viver dignamente, ou seja, onde a vida acontece. Com isso, se dá início às novas possibilidades de organização da produtividade e valorização espacial e cultural, em que a busca pelo reconhecimento da natureza renova o olhar de pertencimento desse meio, categorizado como área de lazer e ambiente para habitar.

O lazer é percebido pelos entrevistados como as ações diárias nos momentos de descanso dos finais de semana, geralmente vivenciadas na comunidade ou mesmo nas propriedades. Nesse 
contexto, o estar com a família e vizinhos é compreendido como momentos de relaxamento e de tranquilidade, cujas opções existentes perto das propriedades são consideradas boas e suficientes. Quando questionados sobre o que é o lazer e o que faltava em suas comunidades, temos algumas respostas:

É quando saímos passear na comunidade e promoções da comunidade e culto. A filha às vezes vai pra Chapecó na filha dela. Não falta nada, tem campo suiço, academia, salão novo e cancha de bocha. (Entrevista 12).

Lazer é depois do serviço descansar, sair, ir em festas, promoções, futebol, sair com a família, saímos todos juntos. Tem bastante coisas boas aqui mas deveria ter mais liberdade pra fazer promoções quando quisemos. (Entrevista 22).

É assistir, passear com a família. Para descansar e divertir gosto de trocar ideias, informações com conhecidos, amigos e no trabalho. (Entrevista 24).

Nesses relatos, o lazer simboliza expressões e práticas de hábitos e costumes da cultura tradicionalista regional, pautada nas relações de convívio familiar e comunitário. Portanto o acesso ao lazer não pode ser vinculado única e exclusivamente à presença de um ou mais indivíduos em determinados ambientes, afinal este é permeado por questões de classes sociais e culturas familiares existentes no tecido social rural. Segundo Martignoni (2013), nas famílias rurais o lazer é simbolizado pelos vínculos com as práticas das sociedades tradicionais, através de laços afetivos, relações pessoais e presença em comunidade, mas também pelas características da sociedade moderna com a organização do tempo, dos espaços, atitudes e interesses.

$\mathrm{Na}$ atualidade, a produtividade agrícola visando ao aumento da renda familiar para garantir condições mínimas de sobrevivência do homem no campo, caracteriza uma tendência que supera as expectativas por espaços de descanso. Essa afirmação pode ser interpretada através das seguintes palavras:

Sobra pouco tempo pra o lazer, mas fazemos uma escala de trabalho para o leite nos fins de semana, pra o descanso, participação na comunidade e visitas. (Entrevista 5).

Segundo Zioli (2015), a confiança nos aprimoramentos tecnológicos impulsionou a esperança da criação de mais tempo nas práticas de lazer, fato este distante da realidade. Como consequência, se tem o desejo cada vez maior pelo trabalho, objetivando agregar renda e satisfazer as necessidades de consumo, sobrevivência e da vida no campo. Esse contexto, aliado à falta de comunicação, convívio social e, em muitos casos, à precariedade de informações técnicas, intensificam tal problemática, uma vez que induzem a isolamentos e atividades individuais ao invés de a ações coletivas.

Conforme observado no Gráfico 1, do total de entrevistados, 50\% citaram o futebol como alternativa de recreação e $46 \%$ tanto para os jogos de bocha quanto para as promoções festivas. Os cultos dominicais, encontro de mães e de idosos, bailes, rodas de chimarrão com os vizinhos, pesca, rodeios, academia ao ar livre, passeios e os jogos de carta nos bares dos salões comunitários também são citados, porém, em menor proporção, apesar de atenderem diferentes faixas etárias, que dividem socialmente os acontecimentos diários e demais novidades ocorridas na semana. 
Gráfico 1- Atividades de lazer mencionadas pelos entrevistados

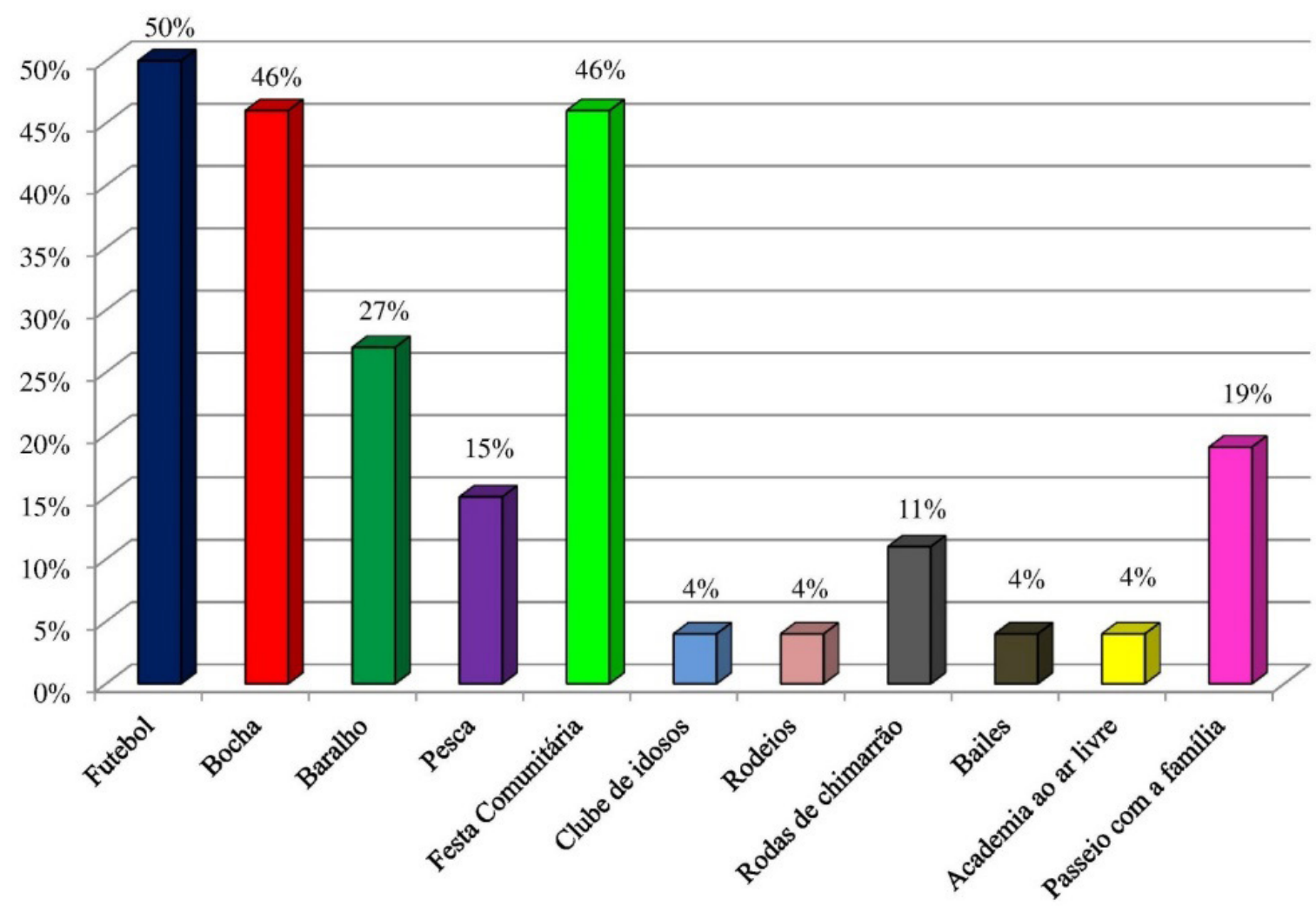

Fonte: Os autores (2017).

Com isso, podemos observar que as alternativas existentes estão pautadas nas relações de convívio familiar e comunitário. Ao recorrermos à literatura, podemos encontrar diversos trabalhos que trazem as visitas e conversas com vizinhos, ida a igreja, encontros e festas na comunidade como forma de lazer para a população rural. Por exemplo, Martignoni (2013) descreve que o lazer deve se relacionar a outros setores, dentre eles o trabalho, educação formal, religião e as obrigações diretamente vinculadas. Do ponto de vista de Schwengber e Pinheiro (2014), as festividades comunitárias se caracterizam como eventos de valor social, por remeterem a um compromisso dos associados perante a comunidade, espaço de lazer e de trabalho.

Cabe aqui fazermos uma análise crítica das alternativas citadas, pois compreender que as idas aos vizinhos, a igreja ou a festas da comunidade são opções de lazer, é simplificar o conceito e o direito das famílias rurais a essas práticas, apesar de serem entendidos e tratados por muitos pesquisadores como tal. Ora, claro que essas atividades são uma forma de descanso e descontração, porém só podemos considerar como lazer, em seu conceito amplo, se essas opções foram escolhidas dentre uma gama variada de alternativas.

Quando pensamos nas opções e infraestruturas ofertadas ao urbano, teremos diversas opções, pois podemos escolher entre variadas atividades públicas e privadas. Já essa situação não acontece no rural, e é justamente essa limitação que criticamos, afinal, o que existe no campo são opções reduzidas de lazer, restando aos moradores se adaptarem às poucas ofertas ou se deslocarem aos centros que possuam mais e melhores alternativas.

Ainda em relação ao Gráfico 1, podemos refletir que, dentre as atividades mais desenvolvidas, estão o futebol, a bocha e o baralho, que podem ser consideradas atividades do gênero masculino. A partir de tal concepção, destacamos: 
O futebol é invariavelmente o terreno privilegiado do lazer masculino nas comunidades rurais, realizado em um campo (que não se constitui apenas em um 'gramado' natural, mas, também, em um fértil ambiente cultural) em que se travam os jogos que atraem as atenções dessas populações e, mais recentemente, o interesse e o olhar crítico feminino. (STROPASOLAS, 2004, p. 260).

Corroborando, Schwengber e Pinheiro (2014, p. 77) afirmam:

Esta realidade se faz ainda muito presente, e parece que mais forte no meio rural, quando percebemos um envolvimento na feitura das festas, bem como uma diferença no trabalho de homens e mulheres. O espaço público é ocupado pelos homens, enquanto as mulheres ficam no espaço privado como o do lar. Antes da festa, os homens responsáveis por providenciar a carne reúnem-se para realizar a tradicional "carneança". E no dia da festa fica a cargo deles assar o churrasco, vender as "fichas" de almoço e de bebidas e contabilizar as despesas e lucros pós-festa. As mulheres reproduzem o espaço do lar: fazem pães e cucas, maionese, preparam saladas, fazem o arroz, os doces, organizam pratos e são responsáveis pela limpeza do salão; também se envolvem com a arrecadação e o sorteio de prêmios, com as lembrancinhas e a organização da missa.

Dessa forma, as atividades de lazer existentes para as mulheres ainda estão muito vinculadas com a questão do lar, da família, filhos, pais, netos e do marido, seja ela como apoiadora nos campeonatos ou a responsável pelos cuidados das crianças nesses momentos de descanso. 0 lazer para as mulheres também é entendido através de trabalhos culturalmente designados como sendo femininos, exemplificando o tricô, a fabricação de pães e o bingo. Porém não é objetivo deste artigo aprofundar teoricamente a cultura do machismo, pois compreendemos que a construção social dessas relações são extensas e complexas e merecem destaque próprio em outro trabalho.

Como exemplos de atividades de lazer simbolizadas possíveis e adequadas ao meio rural, Zioli (2015) cita as de interesse associativo que consentem o contato e convívio através da aproximação com os demais indivíduos e do encontro face a face com a família e amigos. Em determinados casos, a relação com as informações transmitidas pelas televisões, internet, e outros meios de comunicação também pode ser vista como momentos de lazer, no entanto, deve-se ter cuidado quando essa prática gera o afastamento dos laços afetivos entre os membros das famílias rurais. De acordo com Pinheiro (2016), o lazer, além de remeter uma liberdade de escolha na ocupação do tempo conforme o estilo de vida, gênero e cultura de cada indivíduo, representa uma opção de diferentes motivações, que, muitas vezes, estão associadas ao convívio social através das redes sociais.

Do número total de entrevistados, 57,69\% estão satisfeitos com as alternativas de lazer existentes no município, e 42,31\% elogiam tais espaços de entretenimento, mas, ao mesmo tempo, veem a necessidade de melhorias, como a implantação de praças, parques, calçadas, campo de vôlei e realização de festas juninas.

Entretanto, quando cruzamos essa análise de satisfação com a análise de gênero e idade, percebemos a baixa permanência da juventude no meio rural, bem como a pequena representatividade das mulheres. Do número total de integrantes das famílias que repassaram as informações, 10,23\% correspondem aos membros idosos, 65,91\% aos adultos, 20,45\% a juventude e 3,41\% as crianças ${ }^{2}$. Já no que se refere ao gênero dos entrevistados, destaca-se que 55,95\% equivalem ao gênero masculino e 44,05\% ao feminino.

\footnotetext{
${ }^{2}$ Como parâmetros utilizados para a delimitação destas faixas etárias, estão os grupos de idade estabelecidos pelo IBGE, na qual as crianças se enquadram até os 4 anos, juventude dos 5 anos aos 19 anos, adultos dos 20 anos aos 64 anos e idosos de 65 anos ou mais.
} 
A partir desses dados, pode ser percebido que existe uma porcentagem considerável de crianças e jovens habitando o espaço rural, fato justificado pelo deslocamento dessa população para os centros urbanos geralmente em fase posterior (aos 18 anos), em busca de novas oportunidades de emprego e melhores condições de vida. Segundo Spanevello et al. (2017), no meio rural, o envelhecimento se tornou uma questão social, pois os jovens veem nas cidades oportunidades promissoras, resultando cada vez mais no envelhecimento dos moradores que permanecem no campo.

O que pode ser observado é que são poucos os espaços de lazer, e aqueles existentes são direcionados aos indivíduos do gênero masculino (20 anos aos 65 anos), marginalizando os segmentos das mulheres e jovens (de acordo com as atividades mais citadas). Quando analisamos a idade dos entrevistados, verificamos que, em sua maioria, estão acima de 40 anos, ou seja, as concepções de lazer e de descanso não condizem com o que os jovens ou as mulheres percebem que seriam momentos de lazer e descanso. Dessa forma, compreendemos por que uma parcela expressiva dos entrevistados está satisfeita com as opções de lazer presentes no município de Saudade do Iguaçu.

Mas, ao rever as falas dos entrevistados, destacamos uma que se refere justamente à falta de opções às mulheres e aos jovens:

Faltam reuniões pra discussão na perspectiva de incentivo ao lazer feminino. (Entrevista 7).

Ao retornamos a fala de Schwengber e Pinheiro (2014), que os espaços ocupados por homens e mulheres são diferentes, eles na esfera pública e elas no privado do lar, as autoras refletem que o lazer no meio rural assume novas características no momento em que as atividades são relacionadas à rotina dos moradores, principalmente das mulheres. Em outras palavras, as festas comunitárias, experiências religiosas e laços de vizinhança simbolizam a crescente afetividade, aprendizagem e sociabilidade, visando reviver a cultura e tradição.

A precariedade de opções de lazer no rural para as mulheres e para os jovens podem ser um dos problemas que afetam diretamente a reprodução social das famílias do campo, pois, sem atrativos para esses segmentos, eles certamente irão migrar para a cidade à procura de alternativas e possibilidades (GODOY et al., 2010). Em estudos realizados, é comprovado que são as mulheres e os jovens que mais saem das áreas rurais, por diversos motivos, mas principalmente pela condição de invisibilidade que o jovem tem perante aos pais no comando da propriedade e pela desvalorização do papel da mulher (CONTAG, 2014).

O protagonismo do jovem do campo, junto com outros atores e parceiros, em detrimento de ações individualizadas e pontuais, desperta o aperfeiçoamento do caráter coletivo, na busca pela qualidade de vida de uma configuração regional, por meio de espaços rurais agradáveis para se conviver (BORGES, 2012).

Diante do exposto, podemos verificar que existem poucas opções de lazer para a população rural, e as existentes remetem à questão de gênero e faixa etária específica, deixando a parcela de jovens e mulheres sem muitas opções de lazer, o que faz com que esses públicos se desloquem à sede do município ou aos polos urbanos regionais para o acesso às atividades de recreação. Por meio deste levantamento de dados, observamos que os lugares de interação e diversão para os momentos de descanso, influenciam diretamente na qualidade de vida no campo e, consequentemente, na permanência das famílias rurais.

Quando analisada a atual conjuntura do rural no que se refere aos estudos de masculinização e envelhecimento, podemos concluir que o município de Saudade do Iguaçu também 
sofre esses fenômenos. Tais fatos por si só já são preocupantes no que tange à reprodução da população campesina, pois é sabido que somente o econômico não tem bastado para superar e reduzir o êxodo rural, portanto teremos que pensar em outros fatores que possam auxiliar a permanência no meio rural.

Contribuindo, Godoy et al. (2010) apontam que somente através da revitalização dos espaços rurais e da valorização do rural é que será possível estimular a permanência dos jovens e das mulheres, por meio de novas estratégias de produção, políticas públicas, infraestrutura e lazer, propiciando o fortalecimento do tecido social rural. Zioli (2015) destaca que o maior enfrentamento está no desafio de aumentar a qualidade de vida das famílias rurais e minimizar as desigualdades sociais através das políticas públicas, bem como incorporar o homem do campo no diálogo com a área urbana.

Ao pensarmos a questão do lazer, esse pode ser um elemento que venha a favorecer a fixação da população no campo, já que com esses momentos se aumenta a qualidade de vida. Afinal, o rural não deve ser concebido como mero local de produção ou lazer para a população urbana, mas deve ser compreendido como espaço de vivência, trabalho e residência.

É necessária a luta por políticas públicas que propiciem novos ambientes de entretenimentos e descanso, configurados por características democráticas e de acesso a todos, adverte Martignoni (2013). Nesse contexto, o autor cita como outro fato relevante, a reconsideração dos aspectos culturais e sociais durante o processo de organização e desenvolvimento dos projetos de lugares interativos, que atualmente se encontram associados à ideia universal de lazer, na qual o próprio espaço orienta as atitudes, desprezando o tecido que dá vida a localidade.

Contudo é imprescindível que se pense a organização e estruturação de locais e atividades de lazer para a população rural, configurando ao nosso olhar uma estratégia para permanência da população no rural. Afinal, o contato social, a facilidade de comunicação, aperfeiçoamento tecnológico e políticas públicas apropriadas podem colaborar para uma melhor qualidade de vida e lazer aos agricultores.

\section{ALGUMAS CONSIDERAÇÕES}

A partir dos resultados encontrados, observamos a importância da compreensão da influência dos ambientes de convívio e lazer no meio rural, bem como na qualidade de vida dos seus moradores, e consequentemente a falta de opções como um dos elementos que contribuem com o êxodo rural. Percebemos que o lazer é algo necessário e formador do bem-estar e da saúde das populações, tanto urbanas quanto rurais. O lazer deve ser observado como prática da manutenção do convívio social, da saúde e do exercício da cidadania, pois sem ele não tem como pensar na construção de consciências críticas e criativas, muito menos na manutenção das populações onde residem.

O rural não é somente local de produção, mas sim um local de moradia e relações sociais, estando desassistido no que tange às estruturas de lazer, sendo assim fundamental a criação de políticas públicas e projetos que visem atender a qualidade de vida pelo viés do lazer. Nesse sentido, Veiga (2002) afirma que elevar os níveis de renda no rural como qualidade de vida, bem como a visão de que urbanização é a única via de desenvolvimento do campo, só é possível para aqueles que desconhecem a diversidade das relações existentes entre urbano e rural dos países desenvolvidos. 
Ao pensarmos sobre os temas pertinentes às famílias do campo, teremos as questões da reprodução social e a sucessão das propriedades com foco nos jovens e nas mulheres, já que vários estudos apontam o êxodo dessa classe juvenil e o processo de masculinização do nosso rural. Dessa forma, torna-se relevante a construção de alternativas e implantação de espaços de lazer, além da conservação daqueles já existentes, para atender a todos os componentes da população campesina. Nesse sentido, nossa reflexão se direciona para a ideia de que, assim, o rural passará a ser concebido e percebido como deve ser, isto é, um espaço multifuncional onde pessoas vivem e trabalham e, tal como, necessitam também de espaços e atividades de lazer.

Tendo em consideração que o presente trabalho não esgotou o debate sobre a temática, esperamos ter contribuído para acrescentar mais um fator a ser pensado sobre a vida da população no campo e que deve ser considerado em futuros estudos e políticas de planejamento. Portanto é necessária a efetivação de políticas públicas, da assistência técnica, extensão rural e demais métodos corporativos que venham a privilegiar a organização e o planejamento desses espaços para a efetivação do desenvolvimento rural sustentável.

\section{REFERÊNCIAS}

BICALHO, Paula Gonçalves et al. Atividade física e fatores associados em adultos de área rural em Minas Gerais, Brasil. Revista de Saúde Pública, São Paulo, v. 44, n. 5, p. 884-93, 2010.

BORGES, Graziela Scopel. A formação do protagonismo do jovem rural a partir da pedagogia da alternância em casas familiares rurais. Orientador: Edival Sebastião Teixeira. 2012. 157f. Dissertação (Mestrado em Desenvolvimento Regional)- Universidade Tecnológica Federal do Paraná, Pato branco, PR, 2012.

CONFEDERAÇÃO NACIONAL DOS TRABALHADORES RURAIS AGRICULTORES E AGRICULTORAS FAMILIARES. Juventude e sucessão rural. Brasília: CONTAG, 2014. Disponível em: www.contag.org.br/imagens/ f2067juventudeesucessaorural.doc. Acesso em: 20 out. 2017.

GODOY, Cristiane Maria Tonetto; PÉREZ, Flávia Inês Carvajal; WIZNIEWSKY, José Geraldo; GUEDES, Ana Cecilia; MORAES, Cleia dos Santos. Juventude rural, envelhecimento e o papel da aposentadoria no meio rural: a realidade do município de Santa Rosa/RS. In: CONGRESSO SOBER: SOCIEDADE BRASILEIRA DE ECONOMIA, ADMINISTRAÇÃO E SOCIOLOGIA RURAL, 48., 25-28 jul. 2010, Campo Grande, MS. Anais [...]. Campo Grande, MS, 2010. [Apresentação oral].

GODOY, Cristiane Maria Tonetto; WIZNIEWSKY, José Geraldo. Papel da pluriatividade no fortalecimento da agricultura familiar do município de Santa Rosa/RS. Desafio Online, Campo Grande, MS, v. 1, n. 3, p. 1-16, set./dez. 2013. Disponível em: http://www.desafioonline.ufms.br/index.php/deson/article/view/1117/732. Acesso em: 6 set. 2017.

HARTWIG, Marisa. Migração campo cidade: trajetórias de vida, trabalho e escolarização de jovens trabalhadores. In: SEMINÁRIO INTERNACIONAL,1.; FÓRUM DE EDUCAÇÃO DO CAMPO DA REGIÃO SUL DO RS: CAMPO E CIDADE EM BUSCA DE CAMINHOS COMUNS, 1., 12-14 nov. 2012, Pelotas, RS. Anais [...]. Pelotas: UFSC, 2012.

INSTITUTO BRASILEIRO DE GEOGRAFIA E ESTATÍSTICA. Dados gerais do município. IBGE, 2017. Disponível em: http://cidades.ibge.gov.br/painel/painel.php?lang=\&codmun=412627\&search=paran\%E1 | saudadedo-iguacu. Acesso em: 1ㅇago. 2017.

MARTIGNONI, Luciano. Lazer no assentamento rural Oito de Junho: análise a partir da multifuncionalidade da agricultura. Orientadora: Hieda Maria Pagliosa Corona. 2013. 128f. Dissertação (Mestrado em Desenvolvimento Regional)- Universidade Tecnológica Federal do Paraná, Pato Branco, PR, 2013. 
MATIAS-PEREIRA, José. Manual de metodologia da Pesquisa científica. 3. ed. São Paulo: Atlas, 2012.

MICHEL, Maria Helena. Metodologia e pesquisa científica em ciências sociais. 2. ed. São Paulo: Atlas, 2009.

MORAIS, Eliane Pinheiro de; RODRIGUES, Rosalina Aparecida Partezani; GERHARDT, Tatiana Engel. Os idosos mais velhos no meio rural: realidade de vida e saúde de uma população do interior gaúcho. Texto \& Contexto Enfermagem, Florianópolis, v. 17, n. 2, p. 374-83, abr./jun. 2008. Disponível em: http://www. scielo.br/pdf/tce/v17n2/21.pdf. Acesso em: 5 set. 2017.

NAHAS, Markus Vinicius. Atividade física, saúde e qualidade de vida: conceitos e sugestões para um estilo de vida ativo. Londrina, PR: Midiograf, 2001.

OLIVEIRA, Cristina Borges. Sobre lazer, tempo e trabalho na sociedade de consumo. Conexões, Campinas, SP, v. 2, n. 1, p. 20-34, 2004.

PASCHOAL, Sérgio Márcio Pacheco. Qualidade de vida do idoso: elaboração de um instrumento que privilegia sua opinião. 2000. 252p. Dissertação (Mestrado em Medicina)- Universidade de São Paulo, São Paulo, SP, 2000.

PEGORARI, Maycon Sousa et al. Prática de atividade física no lazer entre idosos de área rural: condições de saúde e qualidade de vida. Revista de Educação Física, Maringá, PR, v. 23, n. 2, p. 233-41, 2015.

PINHEIRO, Naíra Letícia Giongo Mendes. Mulheres rurais e a experiência de lazer no facebook. In: ANPED SUL- REUNIÃO CIENTÍFICA REGIONAL DA ANPED, 11., 24-27 julho, Curitiba, 2016. Anais [...]. Curitiba: UFPR, 2016. Disponível em: http://www.anpedsul2016.ufpr.br/wp-content/uploads/2015/11/eixo18_NAIRALETICIA-GIONGO-MENDES-PINHEIRO.pdf. Acesso em: 12 out. 2017.

SAUDADE DO IGUAÇU (Cidade). Prefeitura Municipal. Histórico. 2017. Disponível em: http:// saudadedoiguacu.pr.gov.br/historico.php. Acesso em: 1ํago. 2017.

SCHWENGBER, Maria Simone Vione; PINHEIRO, Naíra Letícia Giongo Mandes. A tríade de lazer de mulheres camponesas do meio rural de Jóia (RS): atividades religiosas, rede de vizinhança e festas comunitárias. Gênero, Niterói, RJ, v. 15, n. 1, p. 69-80, 2014. Disponível em: http://www.revistagenero.uff.br/index.php/ revistagenero/article/view/635/389. Acesso em: 12 out. 2017.

SPANEVELLO, Rosani Marisa; MATTE, Alessandra; ANDREATTA, Tanice; LAGO, Adriano. A problemática do envelhecimento no meio rural sob a ótica dos agricultores familiares sem sucessores. Desenvolvimento em Questão, ljuí, RS, ano 15, n. 40, p. 348-72, jul./set. 2017. Disponível em: https://www.revistas.unijui. edu.br/index.php/desenvolvimentoemquestao/article/view/5903/5403. Acesso em: 6 set. 2017.

STROPASOLAS, Valmir Luiz. O valor (do) casamento na agricultura familiar. Estudos Feministas, Florianópolis, v. 12, n. 1, p. 253-67, jan./abr. 2004. Disponível em: https://periodicos.ufsc.br/index.php/ref/article/view/ S0104-026X2004000100013/8697. Acesso em: 12 out. 2017.

VEIGA, J. E. da. A face territorial do desenvolvimento. Interações - Revista Internacional de Desenvolvimento Local, Campo Grande, MS, v. 3, n. 5, p. 5-19, set. 2002.

ZIOLI, Osni. O lazer dos agricultores familiares promotores do turismo: o caso do Roteiro Turístico Caminhos do Marrecas no Sudoeste do Paraná. Orientador: Hieda Maria Pagliosa Corona. 2015. 175f. Dissertação (Mestrado em Desenvolvimento Regional)- Universidade Tecnológica Federal do Paraná, Pato Branco, PR, 2015. 


\section{Sobre autores:}

Celí Maziero: Mestranda em Desenvolvimento Regional pela Universidade Tecnológica Federal do Paraná (UTFPR), na Linha de Pesquisa em Ambiente e Sustentabilidade. Especialista em Engenharia de Segurança do Trabalho e graduada em Arquitetura e Urbanismo pela Universidade do Oeste de Santa Catarina. Trabalha como Arquiteta e Urbanista da Prefeitura Municipal de São Miguel do Oeste, e leciona no curso de Arquitetura e Urbanismo da Universidade do Oeste de Santa Catarina. E-mail: celimaziero1@ hotmail.com, Orcid: http://orcid.org/0000-0002-7071-2762

Cristiane Maria Tonetto Godoy: Bolsista pós-doutorado em Desenvolvimento Regional pela Universidade Tecnológica Federal do Paraná (UFTPR), Campus Pato Branco. Doutorado e mestrado em Extensão Rural e Graduação em Agronomia, pela Universidade Federal de Santa Maria. Atuou também como tutora a distância da Universidade Aberta do Brasil - UFSM e como assessora territorial de gestão social do projeto Nedet/MDA. E-mail: guriaccr@hotmail.com, Orcid: http://orcid.org/0000-0001-6150-9976

José Ricardo da Rocha Campos: Doutor em ciências, área de concentração Solos e Nutrição Mineral de Plantas, pela Escola Superior de Agricultura Luiz de Queiroz (ESALQ/USP). Mestrado em Produção Vegetal e graduação em Agronomia pela Universidade Federal dos Vales do Jequitinhonha e Mucuri (UFVJM). Atuou nas seguintes áreas: Gênese, Morfologia e Classificação do Solo com ênfase na relação Solo/Paisagem; na relação entre a morfoestratigrafia e a formação do solos e Geofísica Rasa com o uso do Radar de Penetração do Solo (GPR). E-mail: jrcampos@utfpr.edu.br, Orcid: http://orcid.org/0000-0002-5162-3158

Nilvania Aparecida de Mello: Pós-doutorado em Filosofia da Ciência pela Université Joseph Fourrier (França). Doutorado em Ciência do Solo pela Universidade Federal do Rio Grande do Sul (UFRGS). Mestrado em Agronomia - Área de concentração física, manejo e conservação do solo,- pela Universidade Federal do Paraná (UFPR). Graduação em Agronomia pela Universidade Estadual de Ponta Grossa (UEPG). Professora da Universidade Tecnológica Federal do Paraná. Tem experiência na área de Agronomia, com ênfase em manejo do solo, atuando principalmente nos seguintes temas: plantio direto, qualidade ambiental, enfoque sistêmico, qualidade da água e do ambiente, educação ambiental. E-mail: nilvania@utfpr.edu.br, Orcid: http://orcid.org/0000-0002-5371-0554 